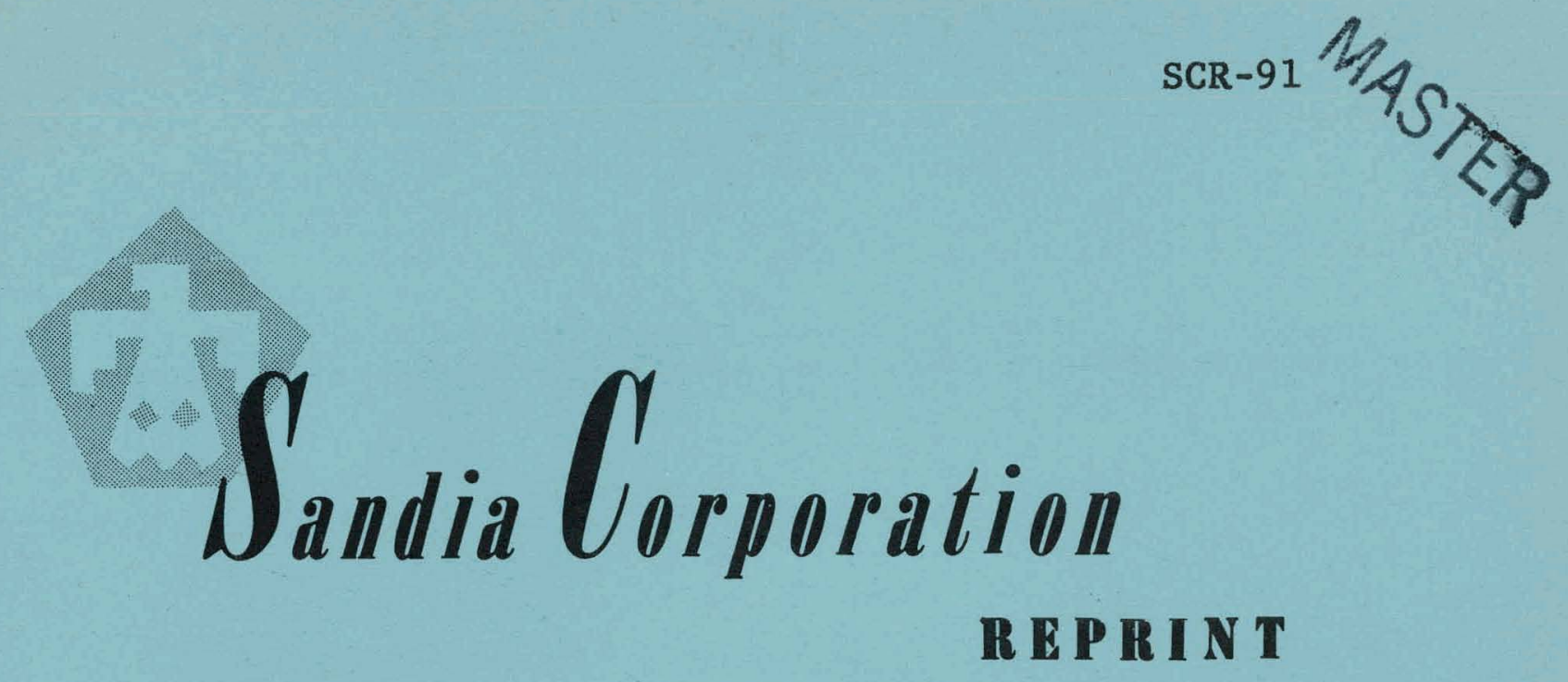

HIGH TIME RESOLUTION TELEMETRY

By mICROWAVE RF LInK

by
C $E$ Ingersoll

mAy 1959 


\section{DISCLAIMER}

This report was prepared as an account of work sponsored by an agency of the United States Government. Neither the United States Government nor any agency Thereof, nor any of their employees, makes any warranty, express or implied, or assumes any legal liability or responsibility for the accuracy, completeness, or usefulness of any information, apparatus, product, or process disclosed, or represents that its use would not infringe privately owned rights. Reference herein to any specific commercial product, process, or service by trade name, trademark, manufacturer, or otherwise does not necessarily constitute or imply its endorsement, recommendation, or favoring by the United States Government or any agency thereof. The views and opinions of authors expressed herein do not necessarily state or reflect those of the United States Government or any agency thereof. 


\section{DISCLAIMER}

Portions of this document may be illegible in electronic image products. Images are produced from the best available original document. 
Presented at IRE SEVENTH REGION CONFERENCE

Albuquerque, New Mexico. May 1959. 
SCR-91

\section{SANDIA CORPORATION REPRINT}

\section{HIGH TIME RESOLUUIUN TELEMETRY BY} MICROWAVE RF LINK

C. E. Ingersoll

May 1959 


\title{
HIGH TIME RESOLUTION TELEMETRY BY MICROWAVE RF LINK
}

\author{
C. E. Ingersoll
}

On Desember 2, 1812, the first main-made, nuclear chain reaction known to us was achieved. Approximately 2-1/2 years later, the first man-made nuclear detonation known to us took place. Somewhere between these two events the nuclear age began.

From that time on, the entire subject of nuclear detonations has necessarily been obscured by security measures of one kind or another. However, during the intervening 15 years, various bits of information have been declassified and have found their way into publication. The gradual lifting of security bans makes it possible tn discuss some of the problems and accomplishments associated with the testing of nuclear explosive systems.

Any number of unclassified texts on nuclear physics contain the basic information with which one can describe a nuclear detonation in some detail. For $\$ 2$. it is possible to purchase a paper-bound handbook entitled "The Effects of Nuclear Weapons" from the United States Government Printing Office in Washington. Quoting from the foreword of this publication: "This handbook, prepared by the Armed Forces Special Weapons Project of the Departinent of Defense in coordination with other cognizant government agencies, and published by the United States Atomic Energy Commission, is a comprehensive summary of current knowledge on the effects of nuclear weapons." Most numbers which will be mentioned are taken directly from this handbook or are derived from numbers and facts which it contains.

In the comparison of nuclear detonations with other nuclear chain reactions such as the more or less ordinary nuclear reactor, the life expectancy of the detonating reactor is quite short. As we shall see, it is less than 1 microsecond. 
For the purpose of this presentation, let us consider a nominal fission system whose explosive energy is equivalent to that of 20,000 tons of TNT. The nuclear fuel of this hypothetical system can be uranium-235 of an unspecified enrichment.

If the $20 \mathrm{kt}$ is converted to units of energy more compatible with nuclear calculations, its equivalence turns out to be on the order of $10^{26} \mathrm{mev}$. A good round number. for the fission energy yield of a single $\mathrm{U}_{235}$ atom is $200 \mathrm{mev}$. To release the $20-\mathrm{kt}$ equivalent, one needs to cause the fission of $10^{24}$ atoms of $\mathrm{U}_{235^{\circ}}$

In elementary reactor theory, a subcritical mass of fissionabie material ic by definition incapable of sustaining a chain reaction. A crilical hiass or adoembly will sit and cook at a more or less stable power level or fission rate, and a supercritical mass or assembly will increase its fission rate exponentially.

The equation for the rate of change of neutrons with time in a reactor is:

$$
\frac{\mathrm{dN}}{\mathrm{dt}}=\mathrm{N} \frac{\delta \mathrm{k}}{\ell}
$$

where $\delta \mathrm{k}$ is the excess reactivity and $\ell$ is neutron life from fission birth to fission absorption.

In a supercritical assembly, the value of $\delta \mathrm{k}$ is a positive number, something greater than 0 , but cannot exceed approximately 1.5 because of the nature of the $\mathrm{U}_{235}$ fission mechanics. To stay in the realm of round numbers, we will take it to be unity.

The value of the constant $\ell$ is given by the handbook (Paragraph 1.36) as approximately $10^{-8}$ seconds in a fast reactor. The value of $\delta k / \ell$ then becomes:

$$
\frac{1}{10^{-8}} \text { seconds }=10^{8} \text { second }^{-1}
$$

or

$$
\frac{\mathrm{dN}}{\mathrm{dt}}=10^{8} \mathrm{~N}
$$

Equation 2 integrated yields the familiar:

$$
N_{t}=N_{o} e^{10^{8} l}
$$

where $N_{t}$ is the number of neutrons at time $t$ and $N_{o}$ is the number at time 0. 
Although we have considered neutron multiplication up to this point, many considerations of the nuclear reaction have this fundamental equation as a basis.

To calculate the time required to complete the detonation, we can equate $\mathrm{N}_{\mathrm{t}}$ with $10^{24}$ atoms of $\mathrm{U}_{235^{\circ}}$. Assuming $\mathrm{N}_{\mathrm{o}}$ to be unity, the equation is:

$$
\begin{aligned}
10^{24} & =\mathrm{e}^{10^{8} \mathrm{t}} \approx \mathrm{e}^{55} \\
\mathrm{t} & \approx 0.55 \mu \mathrm{s} .
\end{aligned}
$$

To calculate the peak power of the system, we can solve Equation 2 after substituting the total number for $\mathrm{N}$.

$$
\frac{\mathrm{dN}_{\mathrm{t}}}{\mathrm{dt}}=10^{8} \times 10^{24}=10^{32} \text { second }^{-1}
$$

$\mathrm{N}$ is the number of fissioned atoms, and $\mathrm{dN} / \mathrm{d}$ the fission rate. A good rule of thumb is that $3 \times 10^{10}$ fissions per second are equal to 1 watt, so the peak power of the detonation is approximately $10^{21}$ watts.

We now have some realistic numbers by which we can examine the problems which relate to the telemetry of information from the detonation.

Several interesting measurements might be made in this hypothetical reactor. The peak-power level, while only of academic interest, could be measured. However, the measurement of the reactor period or e-folding time is of greater interest.

Paragraphs 1.44 through 1.46 of the handbook outline two methods for converting subcritical assemblies into supercritical assemblies. In one method, a spherical assembly of conventional high explosives surrounds a subcritical sphere of fissionable material. A number of detonators placed around the surface of the HE sphere are fired simultaneously. This results in a somewhat symmetrical implosion with shock waves arriving at the fissionable material in spherical symmetry to compress that material. If a given subcritical mass of material is sufficiently compressed, if its density is, thereby, sufficiently increased, the neutron leakage is reduced, and the assembly becomes supercritical. The degree of supercriticality or, in other words, the excessive nuclear reactivity of the assembly is a function of the degree of its compression. If our hypothetical explosive system were of this type, its designer might desire a check on the functioning of the high-explosive system. Since the HE system is designed to produce a particular degree of 
compression with an associated $e$-folding time, a measurement of the e-folding time could be used to check the HE system among other things.

Referring to the telemetry system with which we will make this measurement of the e-folding time, the recording station must be located at some distance from the site of the detonation to safeguard it from destruction. The distance will depend upon whether or not the recording system is manually operated and monitored or whether it is automatically or remotely controlled. A major factor in the choice of equipment location is the method of telemetry.

In our hypothetical test operation we will use a radlu-linked system opcrating in the microwave region. With an RF system therc is little more difficulty involved in operating over 10 miles than over 1 mile. Experience has shown us that 10 miles is ample from the point of view of blast damage, thermal radiation damage, or nuclear radiation damage. Another advantage of an RF system is its ability to operate under conditions which prohibit the laying of cables between zero site and recording stations.

Because the radio link has been described in other papers ${ }^{1}$ (though not at this conference and not as an adjunct to nuclear tests), little more than a cursory description is required at this time. A sufficient signal-to-noise ratio is possible if the signal strength at 10 miles is on the order of $-80 \mathrm{dbm}$. This signal level is readily attained through the use of commercially available tubes and antennas. The Western Electric 431-A klystron, operating in the 4000-megacycle region, will put a minimum of 100 milliwatts into practical high-gain antennas such as horns with $15-$ to $20-\mathrm{db}$ gain or parabolic dishes with 30 - to $40-\mathrm{db}$ gain.

If the signal level were a problem, recent developments in the TWT amplifier field would have eliminated the problem. For example, sperry Gyroscope has recently advertised an amplifier, designated the STS-101, capable of CW operation at 200 watts in the range 2000 to 4000 megacycles. The small signal gain of this amplifier is said to be $40 \mathrm{db}$, so 20 milliwatts from the 431 -A klystron would drive it to its rated output.

One of the transducers used, a scintillation detector, was described earlier by Mr. Brumley. Assuming a peak linear output from the detector of something like 40 volts, the klystron output can be deviated about 25 megacycles. The discriminator output is then on the order of 1 volt.

The data received at the recording station are presented on raster oscilloscopes and single-sweep oscilluscopes and are recorded photographically. 
Rather than dwell with the hardware, I would like to complete this presentation with some comments on time scales and the limiting factors relative to them. At one end of the period of time available for the procurement and transmission of information, one runs into the problem of sampling statistics. The scintillation detector samples the gamma radiation from the nuclear reaction, and a detector of reasonable size can observe only a small portion of the total $4 \pi$ radiation. I do not have any kind of quantitative statistical analysis of the problem, so let it suffice to say data obtained prior to the fifteenth generation, that is, prior to the time at which $\beta$ t in the exponential equation is equal to 15 , are not statistically seceptable. And, in fact, data prior to the twenlieth generation are suspect. If this were the only limitation, there would be an additional one-third microsecond in which to sample; however, it is not the only limitation.

The other limitation is considerably more difficult to describe quantitatively. We have known for some time that an RF signal, originating at or near the site of a nuclear detonation, ceases at a time prior to the transmitter's being destroyed. Data collected over the years have given us some idea of when or at what point of the reaction the signal is interrupted, but only recently have we been able to feel we can assess the many parameters affecting RF propagation.

The presence of ionizing radiation from the nuclear reaction is readily observable. A considerable volume of air surrounding the reaction is ionized, and the electron density is a function of time and distance from the reaction. The effect of high electron densities on RF propagation in space has been described by many people, but most of our work in this area is based on the work of Pawsey and Bracewell. ${ }^{2}$

There are several possible approaches to the problem, but integral to the solution is the need to express the electron density along the path of propagation. Starting at the source of the ionizing nuclear radiation, the source strength varies with time as:

$$
S=K_{1} e^{\beta t} \text { second }^{-1}
$$

a variation of Equation 2.

The integrated radiation flux at distance $r$ from the source is:

$$
\mathrm{N}_{\gamma_{r}}=\frac{\mathrm{K}_{1} \mathrm{e}^{\beta \mathrm{t}}}{4 \pi \mathrm{r}^{2}}=\mathrm{K}_{2} \frac{\mathrm{e}^{\beta \mathrm{t}}}{\mathrm{r}^{2}}
$$


but the actual flux at $r$ is also dependent upon the appreciable time required for the radiation to travel to $r$, so the expression is more accurately:

$$
N_{\gamma_{r}}=\frac{K_{2} e^{\beta(t-r / c)}}{r^{2}} .
$$

Assuming the recombination time to be long compared with the time scale involved, the electron density is proportional to the integrated flux or:

$$
N_{e}=K_{3} \frac{e^{\beta(t-r / c)}}{r^{2}}
$$

From Pawsey and Bracewell we define a value $x$ as:

$$
x=\frac{81 \mathrm{~N}^{\left(\mathrm{m}^{-3}\right)}}{\mathrm{f}^{2}}
$$

where $f$ is the radio frequency whose propagation we are examining. From the same source we also note these relationships:

$$
n=(1-x)^{1 / 2}
$$

where $\mathrm{n}$ is the complex refractive index of the ionized gas or air, and

$$
K_{f}=\frac{2 \pi}{\lambda}(x-1)^{1 / 2}
$$

where $K_{f}$ is the field attenuation constant in nepers per unit length and $\lambda$ is the wavelength of the RF.

For values of $x$ less than unity, the refractive index is real, and the two effects on propagation are a change in phase velocity and a deviation or bending of the RF beam as it passes through regions of different refractive indices.

As $x$ approaches unity, the refractive index approaches zero, and, at a critical electron density, the index is zero and normal propagation ceases. For electron densities greater than this critical value, the nonabsorptive attenuation, actually reflection of the RF, is enormous. An example in Pawsey and Bracewell 
states, "at an electron density one percent above the critical value a $300-\mathrm{mc}$ wave would be attenuated 628 nepers, (or something over $4200 \mathrm{db}$ ) in one kilometer."

If the nonabsorptive attenuation were the only effect; our RF signal would be attenuated approximately $30 \mathrm{db}$ in a kilometer at a time corresponding to the fortyfifth generation. Or, stated in another way, that point in the RF wave train containing data corresponding to the forty-fifth generation would suffer $30-\mathrm{db}$ attenuation in 1 kilometer. With no more than a 30 -db signal-to-noise ratio, this marks rather conclusively the end point of our measurements. Summing up, we have no more than a quarter microsecond in which to take data, modulate the transmitter, and get the RF away from the antenna before going out of business.

The analyses of the other three attenuating mechanisms, phase shift, deviation of the beam, and the effect of magnetic fields (not previously mentioned), have not been completed. The one certain thing we know of them is that they cannot improve the situation. 


\section{LIST OF REFERENCES}

1. Glass, - R. F., "A Wide-Band Mlcrowave Link for" Telentelering", InE Transactions on Telemetry and Remote Control, April 1957.

2: Pawsey, J. L., and Bracewell, R. M. , Radio Astronomy, University Press, Oxford, 1955. 